\title{
Transpalatal distraksiyonun faringeal havayolu boyutları üzerindeki etkilerinin araştırılması
}

\author{
Hüseyin Can Tükel (iD), ${ }^{1 *}$ \\ Mehmet Emre Benlidayı iD,${ }^{1}$ Ufuk Tatı iD,${ }^{1}$ \\ Aslıhan Uzel (iD), ${ }^{2}$ Selen Begüm Uzun, ${ }^{3}$ \\ Mehmet Kürkçü ${ }^{1}$ \\ ${ }^{1}$ Ağız, Diş ve Çene Cerrahisi Anabilim Dalı, Diş Hekimliği \\ Fakültesi, ${ }^{2}$ Ortodonti Anabilim Dalı, Diş Hekimliği Fakültesi, \\ Çukurova Üniversitesi, Adana, ${ }^{3}$ Biyoistatistik Anabilim Dalı, \\ Tıp Fakültesi, Ankara Üniversitesi, Ankara, Türkiye
}

\section{Özet}

AmAÇ: Bu çalışmanın amacı, transvers maksiller darlığı (TMD) olan yetişkin hastalarda transpalatal distraktör ile yapılan cerrahi destekli maksiller genişletmenin (TPD+CDMG) faringeal havayolu boyutları üzerindeki etkisini araştırmaktır.

GeReÇ VE YönTEM: Bu çalışmaya 5 mm'den fazla TMD'si olan hastalar dahil edildi. Bütün hastalara genel anestezi altında, standart Le-Fort I osteotomisi ve maksillada orta hat osteotomisini takiben maksiller genişletme uygulandı. Dört ay sonrasında apareyler çıkartılarak transpalatal ark uygulandı. Hemen ameliyat öncesinde ve distraktör sökümünden en az 6 ay sonra alınan konik ışınlı bilgisayarlı tomografi görüntüleri üzerinde Dolphin 3D Surgery Görüntüleme yazılımının havayolu modülü kullanılarak, faringeal havayolunun nazofaringeal, retropalatal, retroglossal bölümlerinin hacimleri ve faringeal havayolunun en küçük kesit alanı ölçüldü. Sürekli değişkenler için normal dağılım varsayımı Shapiro-Wilk testi ile kontrol edildi ve dağılım tipine göre testler seçildi. Bağımlı yapıda olan TPD+CDMG öncesi ve sonrası ölçümler arasındaki farklılık test edilirken, normal dağılıma sahip olan ölçümler için eşleştirilmiş t-testi, normal dağılıma sahip olmayan ölçümler için ise Wilcoxon testi kullanıldı. İstatistiksel anlamlılık düzeyi $\mathrm{p} \leq \mathbf{0 . 0 5}$ olarak kabul edildi.

BulgulaR: Çalışmaya 9'u kadın (\%42.9), 12'si erkek (\%57.1), toplam 21 hasta dahil edildi. Hastaların yaş ortalaması 22.8 \pm 5.7 ; takip süresi ortalaması $22 \pm 11.1$ ay olarak bulundu. Retropalatal, retroglossal ve toplam havayolu

Makale gönderiliş tarihi: 2 Haziran 2019; Yayına kabul tarihi: 8 Nisan 2020 *iletișim: Dr. Hüseyin Can Tükel, Cukurova Universitesi, Diş Hekimliği Fakültesi, Ağız, Diş ve Çene Cerrahisi Anabilim Dalı, Adana, Türkiye; E-posta: cantukel@gmail.com hacmi ve faringeal havayolunun minimum kesit alanı için TPD+CDMG öncesi ve sonrasında yapılan ölçümler arasında istatistiksel olarak anlamlı fark bulunamadı. Ancak, nazofarinks hacmi için TPD+CDMG öncesi ve sonrası ölçümler arasında anlamlı fark tespit edildi $(p \leq 0.05)$.

Sonuç: TPD+CDMG sonrası nazofarinks hacminde önemli artış olduğu bulunurken, faringeal havayolunun diğer bölgelerindeki hacimsel ve kesitsel değişikliklerin önemli düzeyde olmadığı bulunmuştur.

Anahtar Kelimeler: Farinks; maksiller genişletme; maksiller osteotomi

Kaynak Göstermek İçin: Tükel HC, Benlidayı ME, Tatlı U, Uzel A, Uzun SB, Kürkçü M. Transpalatal distraksiyonun faringeal havayolu boyutları üzerindeki etkilerinin araştırılması. Acta Odontol Turc 2020;37(3):64-70

Editör: Emine Kaygısız, Gazi Üniversitesi, Ankara, Türkiye

YAYıN HAKKI: @ 2020 Tükel ve ark. Bu eserin yayın hakkı Creative Commons Attribution License ile ruhsatlandırılmıştır. Sınırsız kullanım, dağıtım ve her türlü ortamda çoğaltım, yazarlar ve kaynağın belirtilmesi kaydıyla serbesttir.

Finansal Destek: Bulunmamaktadır.

ÇıKAR ÇATıŞMASı: Bulunmamaktadır.

[The abstract in English is at the end of the manuscript]

\section{Giriş}

Transvers maksiller darlık (TMD) izole bir problem olabileceği gibi daha karmaşık dentofasiyal deformitenin bir parçası olarak da ortaya çıkabilir. Çapraz kapanış, çapraşık dişler, ark uzunluğu uyuşmazlığı, karanlık bukkal koridorlar ve derin-dar damak kubbesi TMD'nin klinik özellikleridir. ${ }^{1}$ TMD'nin estetik ve fonksiyonel problemlerin yanında solunum ile ilgili problemlere de yol açabileceği düşünülmektedir. Son yıllarda TMD ve obstrüktif uyku apnesi arasındaki ilişki dikkat çekmiştir.

Obstrüktif uyku apnesi, faringeal hava yolunun uyku sırasında tekrarlayan kollapsından kaynaklanır ve hipoksemiye, hiperkapniye ve intratorasik basınçta dalgalanmalara, bunların sonucu olarak da kardiyovasküler ve serebrovasküler problemlere yol açar. ${ }^{2}$ Havayolu açıklığının sağlanması genellikle uykudan uyanmayı gerektirir. Birey uyanıkken, koruyucu mekanizmalar, faringeal dilatatör kasların aktivitesini artırır. Ancak uyku 
sırasında, bu mekanizmalar başarısız olarak faringeal hava yolunun kollabe olmasına neden olabilir. ${ }^{2-5}$ Faringeal kollaps sıklıkla velofarinks, orofarinks veya her ikisinde birden görülür. ${ }^{6}$ Yapılan araştırmalarda, havayolu morfolojisi ile obstrüktif uyku apnesi arasında bir bağlantı olduğu gösterilmiştir. ${ }^{7}$ TMD dolayısıyla daralmış olan nazal kavite, hava akışına direnci artırmaktadır. ${ }^{8-11}$ Cerrahi destekli maksiller genişletme (CDMG), yetişkin hastalarda TMD'yi düzeltmek için uzun zamandır kullanılmaktadır. CDMG diş destekli hyrax gibi bir apareyle veya tamamen kemik destekli transpalatal distraktör (TPD) gibi bir aparey ile yapılabilir. Bu prosedürde esas amaç, daralmış maksillanın genişletilmesi ile alt-üst dental ark arasındaki uyumsuzluğun giderilmesi olsa da, maksillanın bazal kısmının transvers yönde genişlemesi eşzamanlı olarak burun ve nazal kavite boyutlarını değiştirmektedir. ${ }^{12}$ Birçok çalışmada CDMG'nin nazal kavite boyutları veya nazal hava akımı üzerine olan etkisi araştırılmıştır. ${ }^{12,13}$ Ancak literatürde sınırlı sayıda çalışmada CDMG'nin faringeal havayolu hacmi üzerine olan etkileri incelenmiştir. Pereiera Filho ve ark. ${ }^{14} 15$ hastada, Hyrax tipi diş destekli bir aparey ile CDMG öncesi ve sonrası konik ışınlı bilgisayarlı tomografi (KIBT) görüntüleri üzerinden faringeal havayolu boyutlarını karşılaştırdıkları çalışmada, işlem öncesi ve sonrasında havayolu hacminde anlamlı istatistiksel fark görülmediğini rapor etmiş̧lerdir. Vinha ve ark. ${ }^{15} 18$ hastada, yine hyrax apareyi ile CDMG öncesi ve sonrası bilgisayarlı tomografi görüntüleri üzerinden faringeal havayolu boyutlarını karşılaştırmışlardır. Vinha ve ark. havayolunun alt kısımlarında istatistiksel olarak anlamlı ölçüde artış olduğunu rapor etmişlerdir. Romulo de Medeiros ve ark. ${ }^{13}$ Hyrax apareyi ile CDMG sırasında pterigo-maksiller osteotomi yaptıkları ve yapmadıkları hastaların havayolu morfolojilerini karşılaştırmışlardır. Yazarlar, nazal kavitede, maksiller sinüslerde, orofarinkste ve ayrıca üst solunum yollarının toplam hacminde önemli hacimsel artış sağlanmadığını rapor etmişlerdir. Bununla birlikte, pterigo-maksiller osteotomi yapılan hastalarda nazofarinks hacminin ve orofarinksin minimum kesit alanının önemli ölçüde arttığı bildirilmiştir.

Literatürde, CDMG'nin üst havayolu boyutları üzerine etkisinin araştırıldığı çalışmalar çoğunlukla nazal kavite üzerine yoğunlaşmıştır. Faringeal havayolu değişikliklerini araştıran az sayıda çalışmada ise hem Hyrax tipi diş destekli bir genişletme apareyi kullanılmış, hem de farklı sonuçlar rapor edilmiştir. TPD+CDMG'nin faringeal havayolu boyutları üzerindeki etkilerinin araştırıldığı bir çalışma bulunmamaktadır. Bu bağlamda, bu çalışmanın amacı, TMD'si olan yetişkin hastalarda TPD+CDMG öncesi ve sonrası faringeal havayolu boyutlarını karşılaştırmaktır.

\section{GeREÇ Ve YönTEM}

Retrospektif kohort çalışması olarak planlanan bu araştırmaya, Ağustos 2012 ile Şubat 2018 arasında, $5 \mathrm{~mm}$ 'den fazla TMD'si olan ve genel anestezi altında TPD+CDMG uygulanan hastalar dahil edildi. Çalış- maya, sendromlu, dudak damak yarıkı, yüz travması hikayesi olan ve kronik hastalığı olan hastalar dahil edilmedi. TPD+CDMG öncesi ve distraktör sökümünden en az 6 ay sonra KIBT görüntüsü olmayan, veya bilgilerinde eksiklik olan hastalar çalışmadan çıkartıldı. Tedavi sürecinden önce, tüm hastalardan aydınlatılmış onam formu alındı. Bu araştırma Çukurova Üniversitesi Girişimsel Olmayan Araştırmalar Etik kurulu tarafından onaylandı (Toplantı-karar no: 66-59). Bütün hastalara genel anestezi altında, nazal septum kesisi yapılmadan ve maksiller segment orta yüzden ayrılmadan; pterigoid osteotominin de yapıldığı standart Le-Fort I osteotomisi ve maksillada orta hat osteotomisi uygulandı. Transpalatal distraktör (Transpalatal Distractor, Depuy Synthes, İsviçre veya Rapid Palatal Expander, KLS Martin, Tuttlingen, Almanya) palatinal bölgeye 2 adet minivida yardımı ile sabitlendi. Aparey aktive edilerek, segmentlerin direnç göstermeden ve kant oluşturmadan birbirinden ayrıldığı teyid edildikten sonra iki santral diş arası yaklaşık $1 \mathrm{~mm}$ açık kalacak şekilde aparey eski haline getirildi. Kanama kontrolü sağlandıktan sonra insizyon hattı 3.0 rezorbe olabilen sütur ile kapatıldı. Postoperatif 7. günden itibaren, distraktör bir sabah bir akşam olmak üzere 2 defa çevrilerek günlük yaklaşık $0.66 \mathrm{~mm}$ distraksiyon uygulandı. Nüks miktarı da göz önünde tutularak, istenilen distraksiyon miktarından birkaç milimetre fazla genişleme sağlandıktan sonra distraktörler sabitlendi. Dört ay sonrasında apareyler çıkartılarak transpalatal ark uygulandı. Hemen ameliyat öncesinde ve distraktör sökümünden en az 6 ay sonra KIBT görüntüleri alındı. Görüntüleme alanı, glabella seviyesinden başlayarak en az 3. servikal omuru içeren bölgeyi kapsayacak şekilde; hastalar ayakta, doğal baş pozisyonunda, dil damakta istirahat halindeyken; ve hastalara prosedür sırasında yutkunmamaları ve nefeslerini tutmaları söylenerek tomografi görüntüleri alındı.KIBT görüntüleri, DICOM formatında saklandı ve Dolphin 3D Surgery Görüntüleme yazılımına aktarıldı (Dolphin Imaging Premium Version 11.95, Chatsworth, Los Angeles, CA, ABD). Tüm ölçümler havayolu ölçümünde tecrübeli bir Ağız, Diş ve Çene Cerrahisi uzmanı tarafından yapıldı. Ölçümler yapılmadan önce KIBT görüntüleri Frankfort Horizontal düzlemi yer düzlemine paralel olacak şekilde ayarlandı. Maksilladaki transvers genişlemenin değerlendirilmesi için, koronal kesitte 1. premolar dişler ve 1. molar dişler hizasından, meziyobukkal tüberküller arası ve palatinal alveol kemiğin en koronal noktası arasındaki mesafeler ölçüldü. Havayolu ölçümü için belirlenen sınırlar Tablo 1 ve Şekil 1'de gösterildi. Havayolu hassasiyeti için yazılımın havayolu ölçümü modülünde -430 ile -500 arasında bir değer seçildi. Belirlenen bölgenin hacimsel analizi, yazılım tarafından gri skala kullanılarak yapıldı. Görüntüdeki en karanlık bölge hava yolunu gösterir ve hacim milimetre küp cinsinden ölçülebilir. Böylece, hava yolunun toplam hacmini ve havayolunun en dar olduğu transvers kesitin alanının değerlendirilmesi mümkün olmuştur. Yazılımın havayolu modülü kullanılarak, önceden tanımlanan alt ve üst sınırlar çizildikten sonra, havayolunun belirli bö- 
Tablo 1. Havayolu ölçümünde kullanılan bölgelerin sınırları

\begin{tabular}{|c|c|c|c|c|}
\hline & Ön & Arka & Üst & Alt \\
\hline Nazofarinks & $\begin{array}{l}\text { Posterior nazal spina (PNS) ile } \\
\text { sella turcica'nın orta noktası (S) } \\
\text { arasındaki çizgi }\end{array}$ & $\begin{array}{l}\text { Sella turcica (S) ile 1. servikal } \\
\text { vertebranın (atlas) ön arkının } \\
\text { sagittal düzlemdeki en üst } \\
\text { noktası arasındaki çizgi }\end{array}$ & Farinksin üst sınırı & $\begin{array}{l}\text { PNS'den geçen } \mathrm{FH} \\
\text { düzlemine paralel çizgi }\end{array}$ \\
\hline Retropalatal & $\begin{array}{l}\text { PNS ile yumuşak damak-dil } \\
\text { birleşiminin en derin konkavitesi } \\
\text { arasında kalan çizgi }\end{array}$ & Farinksin arka duvarı & $\begin{array}{l}\text { PNS'den geçen FH } \\
\text { düzlemine paralel } \\
\text { çizgi }\end{array}$ & $\begin{array}{l}\text { Yumuşak damak-dil } \\
\text { birleşiminin en derin } \\
\text { konkavitesinden geçen FH } \\
\text { düzlemine paralel çizgi }\end{array}$ \\
\hline Retroglossal & $\begin{array}{l}\text { Yumuşak damak-dil birleşiminin en } \\
\text { derin konkavitesi ile dilin arka duvarı }\end{array}$ & Farinksin arka duvarı & $\begin{array}{l}\text { Yumuşak damak-dil } \\
\text { birleşiminin en derin } \\
\text { konkavitesinden } \\
\text { geçen FH düzlemine } \\
\text { paralel çizgi }\end{array}$ & $\begin{array}{l}\text { 3. servikal vertebranın en } \\
\text { infero-anterior noktasından } \\
\text { geçen FH düzlemine paralel } \\
\text { çizgi }\end{array}$ \\
\hline Toplam havayolu & $\begin{array}{l}\text { PNS ile S arasındaki çizgi ve } \\
\text { yumuşak damak ile dilin arka duvarı }\end{array}$ & Farinksin arka duvarı & Farinksin üst sınırı & $\begin{array}{l}\text { 3. servikal vertebranın en } \\
\text { infero-anterior noktasından } \\
\text { geçen FH düzlemine paralel } \\
\text { çizgi }\end{array}$ \\
\hline
\end{tabular}

lümlerinin hacmi ve havayolunun en küçük kesit alanı ölçülmüştür.

\section{İstatistik analizler}

Çalışmada değişkenler ortalama \pm standart sapma, medyan (minimum-maksimum) değer şeklinde özetlenmiştir. Değişkenler için normal dağılım varsayımı Shapiro-Wilk testi ile kontrol edilmiş ve dağılım tipine göre testler seçilmiştir. Bağımlı yapıda olan TPD+CDMG öncesi ve TPD+CDMG sonrası ölçümler arasındaki farklılık test edilirken normal dağılıma sahip olan ölçümler için eşleştirilmiş t-testi, normal dağılıma sahip olmayan ölçümler için ise Wilcoxon testi kullanılmışırı. Yapılan ölçümlerin güvenilirliğinin değerlendirilmesi için, rastge- le seçilen 10 hastanın görüntüleri üzerinde,aynı araştırmacı tarafından 30 gün ara ile ikinci kez ölçümler yapılarak gözlemci-içi uyum değerlendirmesi yapılmış ve sınıf içi korelasyon katsayıSı (SKK) değerleri sunulmuştur. SKK'nin yorumlanmasında kappa katsayısına benzer şekilde Landis ve Koch $^{16}$ tarafından önerilen kritik değerler kullanıldı. Uyum için, SKK<0.20: kötü uyum, $S K K=0.21-0.40$ : düşük uyum, $S K K=0.41-0.60$ : orta düzeyde uyum, $S K K=0.61-0.80$ : iyi düzeyde uyum ve SKK=0.81-1.00: yüksek uyum olarak belirlendi. Değerlendirmelerde, $\mathrm{p} \leq 0.05$ istatistiksel olarak anlamlı kabul edilmiştir. Verilerin analizinde IBM SPSS 19 paket programı (IBM Corp. Released 2010. IBM SPSS Statistics for Windows, Version 19.0. Armonk, NY, ABD) kullanılmıştır.

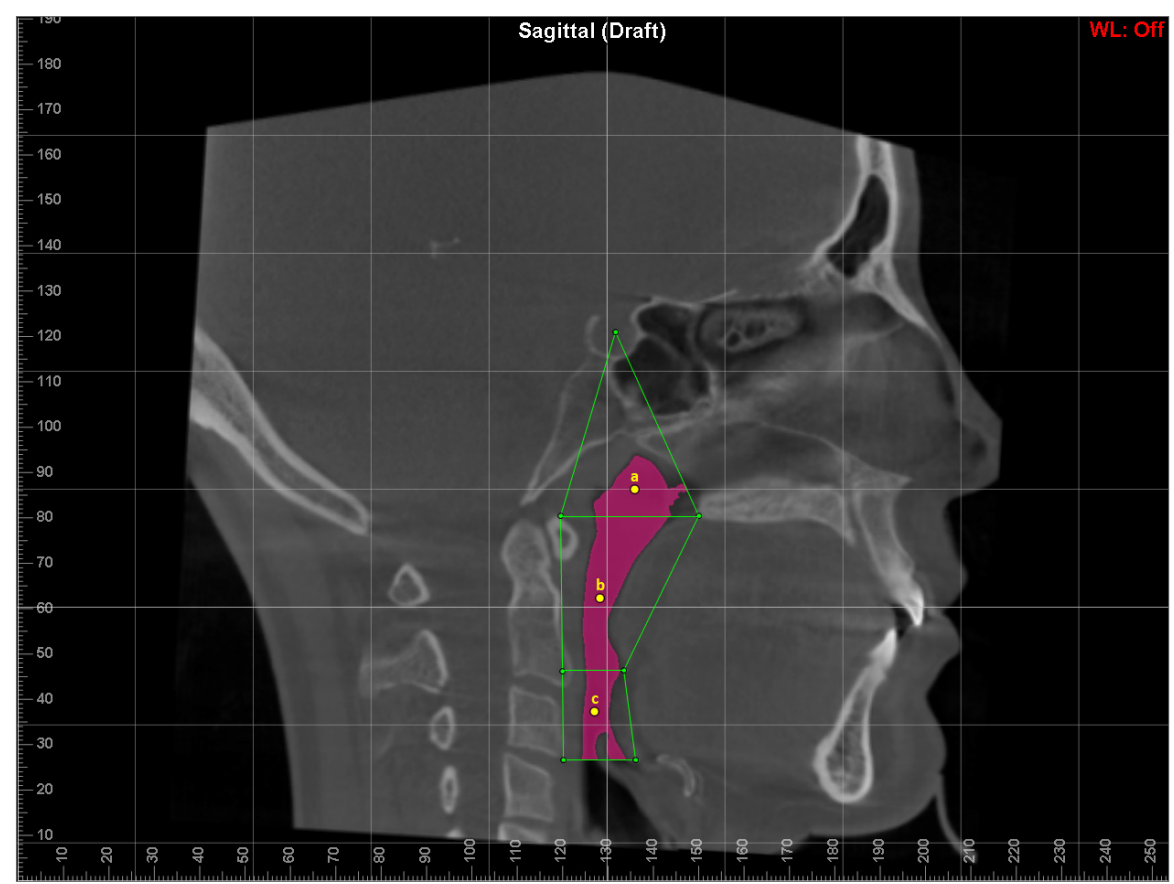

Şekil 1. Havayolu ölçümünde kullanılan bölgelerin sınırları; (a) Nazofaringeal havayolu, (b) Retropalatal havayolu, (c) Retroglossal havayolu 
Tablo 2. TPD+CDMG öncesi ve sonrası ölçümler için sını içi korelasyon katsayısı değerleri (ortalama \pm standart sapma)

\begin{tabular}{|c|c|c|c|c|c|c|}
\hline & \multicolumn{3}{|c|}{ TPD+CDMG öncesi } & \multicolumn{3}{|c|}{ TPD+CDMG sonrası } \\
\hline & $\begin{array}{l}\text { İlk } \\
\text { değerlendirme }\end{array}$ & $\begin{array}{l}\text { İkinci } \\
\text { değerlendirme }\end{array}$ & SKK & İlk değerlendirme & $\begin{array}{l}\text { İkinci } \\
\text { değerlendirme }\end{array}$ & SKK \\
\hline 16-26 kemik (mm) & $30.4 \pm 4.6$ & $30.2 \pm 4.9$ & 0.994 & $35.5 \pm 4.1$ & $35.8 \pm 4.2$ & 0.995 \\
\hline $\begin{array}{l}\text { 16-26 meziyobukkal } \\
\text { tüberkül }(\mathrm{mm})\end{array}$ & $46.5 \pm 6.7$ & $46.8 \pm 6.3$ & 0.995 & $52.9 \pm 6.1$ & $52.5 \pm 6.4$ & 0.990 \\
\hline 14-24 kemik (mm) & $22.8 \pm 2.9$ & $23.5 \pm 3.6$ & 0.921 & $28.1 \pm 3.8$ & $28.3 \pm 2.9$ & 0.921 \\
\hline 14-24 bukkal tüberkül (mm) & $33.7 \pm 7.6$ & $34.6 \pm 7.6$ & 0.988 & $41.1 \pm 5.4$ & $41.3 \pm 5.4$ & 0.992 \\
\hline Nazofarinks $\left(\mathrm{mm}^{3}\right)$ & $3610.2 \pm 1282.3$ & $3807.9 \pm 1336.6$ & 0.891 & $3891.6 \pm 2414.5$ & $4016.6 \pm 2441.3$ & 0.999 \\
\hline Retropalatal $\left(\mathrm{mm}^{3}\right)$ & $9204.7 \pm 2047.1$ & $9270.1 \pm 2443$ & 0.945 & $9626.1 \pm 3247.4$ & $9786.4 \pm 3750$ & 0.989 \\
\hline Retroglossal $\left(\mathrm{mm}^{3}\right)$ & $6153.4 \pm 3143.5$ & $5820.7 \pm 2500.3$ & 0.967 & $7078.1 \pm 3279.3$ & $7096.7 \pm 3171.5$ & 0.982 \\
\hline Toplam $\left(\mathrm{mm}^{3}\right)$ & $18968.3 \pm 4595$ & $18898.7 \pm 4037.5$ & 0.958 & $20595.8 \pm 5614.1$ & $20899.7 \pm 5985.1$ & 0.995 \\
\hline Minimum kesit alanı $\left(\mathrm{mm}^{2}\right)$ & $158.4 \pm 75$ & & & $196.3 \pm 76.4$ & & \\
\hline
\end{tabular}

SKK: Sınıf içi korelasyon katsayısı

\section{BULGULAR}

Transvers maksiller darlık nedeni ile TPD+CDMG uygulanan 32 adet hasta tespit edildi. Bu hastalardan 1'i dudak damak yarıklı olduğu için, 10'u ise ameliyat öncesi veya sonrası KIBT görüntülerinden biri eksik olduğu için çalışmadan çıkartıldı. Sonuç olarak toplam 21 hasta çalışmaya dahil edildi. Bu hastaların 9'u (\%42.9) kadın, 12'si (\%57.1) ise erkek bireylerden oluşmaktadır. Hastaların yaş ortalaması $22.8 \pm 5.7$; takip süresi ortalaması $22 \pm 11.1$ ay olarak bulunmuştur. Çalışmaya dahil edilen bireylerin belirli kısmına ait sonuçlar aynı araştırmacı tarafından iki kere değerlendirilerek, yapılan değerlendirmelere ait güvenilirlik test edilmiştir. Değerlendirmeler sonucunda elde edilen SKK değerleri oldukça yüksek bulunmuş ve sonuçlar Tablo 2'de gösterilmiştir. Minimum kesit alanı değeri için, Dolphin yazılımı, her iki değerlendirmede de araştırmacının ölçümünden bağımsız olarak aynı değerleri bulduğu için güvenilirlik testi yapılmamıştır. Yapılan istatistiksel değerlendirme göz önüne alındığında, 1. premolar dişlerin bukkal tüberkülleri arasındaki mesafe, 1. premolar dişlerin palatinal alveol kemiğinin en koronal noktası arasındaki mesafe, 1. molar dişlerin meziyobukkal tüberkülleri arasındaki mesafe ve 1. molar dişlerin palatinal alveol kemiğinin en koronal noktası arasındaki mesafe için TPD+CDMG öncesi ve sonrası ölçümler arasında anlamlı fark tespit edilmiştir. Retropalatal, retroglossal ve toplam havayolu hacmi ve faringeal havayolunun minimum kesit alanı için TPD+CDMG öncesi ve sonrası yapılan ölçümler arasında istatistiksel olarak anlamlı fark bulunamamıştır. Nazofarinks hacmi için TPD+CDMG öncesi ve sonrası ölçümler arasında anlamlı fark tespit edilmiştir $(p \leq 0.05)$ (Tablo 3$)$.

\section{TARTIŞMA}

Transvers maksiller darlığın, iyi bilinen morfolojik sorunların yanında havayolu problemlerine de yol açtığı düşünülmektedir. Literatürde, iskeletsel gelişimi tamamlanmamış bireylerde, diş destekli genişleticiler ile yapılan hızlı maksiller genişletme (HMG) veya yetiş- kinlerde CDMG'nin üst hava yolları üzerindeki etkileri araştırılmış olmasına rağmen birbirinden farkı sonuçlar rapor edilmiştir.

Langer ve ark. ${ }^{17}$ lateral sefalogramlar üzerinde yaptıkları ölçümlerde, HMG'nin sagittal nazofaringeal alan üzerinde bir etkisi olmadığını bildirmektedir. Aynı şekilde, Usumez ve ark. ${ }^{18}$ tarafından yapılan bir sefalometri çalışmasında, HMG sonrası nazofaringeal havayolu boyutlarındaki değişikliklerin istatistiksel olarak anlamIı olmadığı bildirilmiștir. Caprioglio ve ark. ${ }^{19}$ HMG'den sonra nazal kavite hacminin ve oksijen satürasyonunun arttığını, apne/hipopne indeksinin azaldığını bildirmişlerdir. Ancak faringeal havayolu hacmindeki artış istatistiksel olarak anlamlı bulunmamıştır.Smith ve ark. ${ }^{20}$ HMG'den sonra nazofaringeal havayolu hacmi için, \%16.2'lik önemli bir artış bildirirken, Ribeiro ve ark. ${ }^{21}$ ve Zeng \& $\mathrm{GaO}^{22}$ havayolu hacminde hiçbir değişiklik olmadığını rapor etmişlerdir. Kurt ve ark. ${ }^{23} \mathrm{HMG}$ ve CDMG yaptıkları iki hasta grubunda nazofaringeal boyutlarda istatistiksel olarak önemli olmayan değişiklikler bulmuşlardır. Buna karşılık, Basçiftçi ve ark. ${ }^{24}$ lateral sefalogramlarda planimetrik ölçümleri kullanarak yaptıkları çalışmada, HMG ve CDMG gruplarında nazofarinks bölgelerinin genişlediğini göstermiştir. Tüm bu çalışmalarda diş destekli ya da diş/doku destekli genişleticiler kullanılmıştır. Akay ve ark. ${ }^{25}$ tarafından nazal hava yolu tıkanıklı̆ı̆ bulunan erişkin hastalar üzerinde yapılan sefalometri çalışmasında, TPD+CDMG'nin, sagittal nazofarinks havayolu boyutlarını ve dil arkasındaki asgari orofaringeal mesafeyi artırdığı bildirilmiştir. Bu çalışmaların büyük kısmında, havayolu üzerindeki ölçümler iki boyutlu sefalometrik analizler üzerinden yapılmıştır. Üç boyutlu, hacimsel analizlerin yapıldığı çalışmalar ise genel olarak nazal kavite hacminde meydana gelen değişiklikler üzerinde yoğunlaşmıştır. Faringeal havayolu hacminin araştııılığı çalışmalar ise sınırlı sayıdadır ve büyük çoğunluğunda maksiller genişletme, diş destekli apareyler ile yapılmıştır.

Nada ve ark. ${ }^{26} 19$ hastada Hyrax+CDMG, 14 hastada TPD+CDMG uyguladıkları çalışmada, genişletme ön- 
Tablo 3. TPD+CDMG öncesi ve sonrası maksilladaki çizgisel ölçümler ve havayolu boyutları ölçümleri [ortalama standart sapma ve medyan (minimum-maksimum)]

\begin{tabular}{|c|c|c|c|c|c|}
\hline & TPD+CDMG Öncesi & TPD+CDMG Sonrası & Ortalama fark & $\begin{array}{l}\text { Ortalama fark } \\
\text { SS }\end{array}$ & $\mathbf{P}$ \\
\hline \multirow[t]{2}{*}{ 16-26 kemik $(\mathrm{mm})^{\dagger}$} & $30.3 \pm 3.8$ & $34.6 \pm 3.7$ & 4.3 & 0.69 & 0.0001 \\
\hline & $30.4(22.6-37.1)$ & 34.5 (26.5-40.9) & & & \\
\hline \multirow[t]{2}{*}{ 16-26 meziyobukkal tüberkül (mm)\# } & $48.2 \pm 5.7$ & $52.4 \pm 6$ & 4.2 & 1.5 & 0.002 \\
\hline & $48.7(35.2-58.3)$ & $53.1(35.6-62.9)$ & & & \\
\hline \multirow[t]{2}{*}{ 14-24 kemik $(\mathrm{mm})^{\dagger}$} & $22.6 \pm 3.2$ & $28.4 \pm 6$ & 5.8 & 1.2 & 0.0001 \\
\hline & $22(17.6-29)$ & $27.9(21.1-49.7)$ & & & \\
\hline \multirow[t]{2}{*}{ 14-24 bukkal tüberkül $(\mathrm{mm})^{\dagger}$} & $35.6 \pm 5.9$ & $43.3 \pm 6.2$ & 7.7 & 1.3 & 0.0001 \\
\hline & $35.7(18.6-48)$ & $42.1(34.6-60.2)$ & & & \\
\hline \multirow[t]{2}{*}{ Nazofarinks $\left(\mathrm{mm}^{3}\right)^{\dagger}$} & $4359.6 \pm 2241$ & $4920.1 \pm 2654$ & 560.5 & 271.4 & 0.05 \\
\hline & 4134 (1015-10651) & 4125 (1046-10872) & & & \\
\hline \multirow[t]{2}{*}{ Retropalatal $\left(\mathrm{mm}^{3}\right)^{\#}$} & $9511.9 \pm 3974.2$ & $10048.7 \pm 5696.1$ & 536.9 & 724.5 & 0.639 \\
\hline & 8819 (3558-20598) & 9441 (2410-27074) & & & \\
\hline \multirow[t]{2}{*}{ Retroglossal $\left(\mathrm{mm}^{3}\right)^{\dagger}$} & $7356.1 \pm 4105.1$ & $7392.6 \pm 3645.9$ & 36.5 & 745.9 & 0.961 \\
\hline & 6468 (2591-16895) & 6565 (2416-13818) & & & \\
\hline \multirow[t]{2}{*}{ Toplam $\left(\mathrm{mm}^{3}\right)^{\dagger}$} & $21227.6 \pm 7579.7$ & $22361.4 \pm 9324$ & 1133.9 & 1236.4 & 0.370 \\
\hline & $20591(10479-41210)$ & $20343(9043-50705)$ & & & \\
\hline \multirow[t]{2}{*}{ Minimum kesit alanı $\left(\mathrm{mm}^{2}\right)^{\#}$} & $177.1 \pm 95$ & $187.8 \pm 104.9$ & 10.7 & 14.8 & 0.414 \\
\hline & $159(71-360)$ & $177(45-500)$ & & & \\
\hline
\end{tabular}

$P \leq 0.05$ anlamlı kabul edilmiştir; ${ }^{\dagger}$ Eşleştirilmiş t-testi; "Wilcoxon testi; SS: Standart sapma

cesi ve sonrası nazal havayolu hacimlerini KIBT görüntüleri kullanılarak karşılaştırmıştır. Nazal havayolu hacminde, Hyrax+CDMG grubunda \%9.7 $\pm 5.6, T P D+C D M G$ grubunda \%12.9 12.7 artış olduğu rapor edilmiştir. Genişletme öncesi ve sonrası havayolu hacimleri arasındaki fark her iki grupta da istatistiksel olarak anlamlıdır. Ancak gruplar arasında anlamlı bir fark bulunamamıştır. Vinha ve ark. ${ }^{15} \mathrm{CDMG}$ yaptıkları 18 erişkin hastada genişletme öncesi ve sonrası faringeal havayolu boyutlarını karşılaştırdıkları çalışmada, özellikle havayolunun epiglottis yakınındaki alt kısımlarında transvers ve sagittal planda ve bu seviyedeki toplam aksiyal kesit alanında önemli artış olduğunu bildirmişlerdir. Smith ve ark. ${ }^{20} 20$ genç erişkinde, HMG'den 3 ay sonra KIBT ile üst hava yolu hacmini değerlendirmiş ve burun boşluğu ve nazofarinks hacminde, palatal ve mandibular düzlem açılarında artışlar olduğunu bildirmişlerdir. Ancak bu çalışmanın sonuçları değerlendirilirken sadece 3 ay sonraki görüntüler üzerinden ölçüm yapıldığı göz önünde bulundurulmalıdır. Maksiller genişletmeden hemen sonra artan havayolu hacminin uzun dönemde azaldığı çeşitli araştırmalarda gösterilmiştir. ${ }^{13,14,27}$ Zhao ve ark. ${ }^{27}$ HMG yaptıkları 24 erişkin olmayan hastada üst hava yolu hacmini değerlendirmiş ve ölçümleri TMD'si olmayan 24 hasta ile karşılaştırmıştır. Transvers maksiller darlığa sahip hastalarda havayolu hacminin anlamlı derecede daha küçük olduğunu ve maksiller genişletmenin orofaringeal hava yolu hacmini arttırmadığını bildirmişlerdir. Pereiera Filho ve ark. ${ }^{14} 15$ hastada, CDMG öncesi ve sonrası KIBT görüntüleri üzerinden faringeal havayolu boyutlarını karşılaştırdıkları çalışmada, işlem öncesi ve genişletmeden 6 ay sonra havayolu hacmin- de anlamlı istatistiksel fark görülmediğini rapor etmişlerdir. Romulo de Medeiros ve ark. ${ }^{13}$ CDMG sırasında pterigo-maksiller osteotomi yaptıkları ve yapmadıkları hastaların havayolu boyutlarını karşılaştırmışlardır. Yazarlar nazal kavitede, maksiller sinüslerde, orofarinkste ve üst solunum yollarının toplam hacminde önemli hacimsel artış sağlanmadığını rapor etmişlerdir. Bununla birlikte, pterigo-maksiller osteotomi yapılan hastalarda nazofarinks hacminin ve orofarinksin minimum kesit alanının önemli ölçüde genişlediği bildirilmiştir. Bizim çalışmamızda da benzer şekilde nazofarinks hacmindeki artış istatistiksel olarak anlamlı bulunurken, havayolunun diğer bölgelerindeki hacimsel artış ve havayolunun en dar kesit alanındaki artış istatistiksel olarak anlamlı bulunmamıştır.Bazı araştırmacılar nazofarinks hacminde görülen bu artışın, damak düzleminin inferior yönde yer değiştirmesi dolayısıyla nazofarinks hacmi artarken orofarinks hacminin azalması sonucu ortaya çıktığını öne sürmüşlerdir. ${ }^{13,20}$ Ancak bizim çalışmamızda, nazofarenks hacmi artarken retroglossal ve retropalatal havayolu hacimlerinde bir azalma görülmemiştir. Nazofarinks hacmindeki artış, transvers yönde genişleyen damak dolayısı ile sert damağa yapışan ve palatal aponörozisi oluşturan damak kasları ve yumuşak dokuların gerginliğinin artması ile açıklanabilir.

Literatürde, CDMG'nin burun boşluğu hacminde anIamlı bir artışa ve hava akımına olan direnç üzerinde azalmaya neden olduğu gösterilmiştir. ${ }^{12}$ Bununla birlikte, orofarengeal havayolu üzerine bir etkisinin olmadığını gösteren daha fazla çalışma mevcuttur. Üst hava yolu hacmindeki herhangi bir artışın, hava akımına direnç veya obstrüktif uyku apnesi gibi patolojik koşullar 
üzerinde nasıl etkilerinin olacağı halen bilinmemektedir. Transpalatal distraksiyonun daha fazla ortopedik genişleme dolayısıyla havayolu üzerinde daha fazla etkisi olacağı düşünülse de, mevcut çalışmada bulunan sonuçlar, CDMG yapılan çalışmalarla benzerlik göstermektedir.

$\mathrm{Bu}$ çalışmanın, özellikle retrospektif dizaynından kaynaklanan bir takım zayıf yönleri bulunmaktadır. Kayıtlarında eksiklik olan hastalar çalışma dışı bırakılmış, örneklem boyutu küçülmüştür. Görüntü elde edilmesi sırasında, hastalardan yutkunmamaları ve nefeslerini tutmaları istenmiş olsa da bunu kontrol etmek her zaman mümkün olmamaktadır. Bu çalışma obstrüktif uyku apnesi olan bireyler üzerinde yapılmamıştır. Ayrıca havayolu hacmi üzerinde kilo ve yumuşak dokulardaki değişikliklerin bir takım etkileri olduğu da unutulmamaııdır. Bu faktörlerin de göz önüne alındığı, TPD+CDMG sonrası hacimsel değişiklikleri araştıran, prospektif, randomize kontrollü çalışmalara ihtiyaç vardır. Ek olarak KIBT ve çeşitli yazılımlar kullanılarak, üst solunum yollarının hacimsel ölçümlerinin yapıldığı çalışmalarda kullanılan anatomik referansların standart olmaması, bu çalışmaların sonuçlarını karşılaştırmayı zorlaştırmaktadır. Dolayısıyla havayolu ölçümünde güvenilir ve tekrarlanabilir ölçümlerin hangi anatomik referanslar ile yapılabileceğini araştıran çalışmalara da intiyaç vardır.

\section{Sonuc}

Transpalatal distraksiyon sonrası nazofarinks hacminde önemli artış olduğu bulunurken, faringeal hava yolunun diğer bölgelerindeki hacimsel ve kesitsel değişikliklerin önemli düzeyde olmadığı bulunmuştur.

\section{KAYNAKLAR}

1. Betts NJ, Vanarsdall RL, Barber HD, Higgins-Barber K, Fonseca RJ. Diagnosis and treatment of transverse maxillary deficiency. Int $\mathrm{J}$ Adult Orthodon Orthognath Surg. 1995;10:75-96.

2. Somers VK, White DP, Amin R, Abraham WT, Costa F, Culebras A et al. Sleep apnea and cardiovascular disease: an American Heart Association/American College of Cardiology Foundation Scientific Statement from the American Heart Association Council for High Blood Pressure Research Professional Education Committee, Council on Clinical Cardiology, Stroke Council, and Council on Cardiovascular Nursing. J Am Coll Cardiol 2008;52:686-717.

3. Wheatley JR, Tangel DJ, Mezzanotte WS, White DP. Influence of sleep on response to negative airway pressure of tensor palatini muscle and retropalatal airway. J Appl Physiol (1985) 1993;75:2117-24

4. Series FJ, Simoneau SA, St Pierre S, Marc I. Characteristics of the genioglossus and musculus uvulae in sleep apnea hypopnea syndrome and in snorers. Am J Respir Crit Care Med 1996;153:1870-4.

5. Carlson DM, Onal E, Carley DW, Lopata M, Basner RC. Palatal muscle electromyogram activity in obstructive sleep apnea. Am J Respir Crit Care Med 1995;152:1022-7.

6. Morrison DL, Launois SH, Isono S, Feroah TR, Whitelaw WA, Remmers JE. Pharyngeal narrowing and closing pressures in patients with obstructive sleep apnea. Am Rev Respir Dis 1993;148:606-11.

7. Neelapu BC, Kharbanda OP, Sardana HK, Balachandran R, Sardana V, Kapoor P, et al. Craniofacial and upper airway morphology in adult obstructive sleep apnea patients: A systematic review and metaanalysis of cephalometric studies. Sleep Med Rev 2017;31:79-90.
8. White $B C$, Woodside DG, Cole $P$. The effect of rapid maxillary expansion on nasal airway resistance. J Otolaryngol 1989;18:137-43.

9. Hartgerink DV, Vig PS, Abbott DW. The effect of rapid maxillary expansion on nasal airway resistance. Am J Orthod Dentofacial Orthop 1987;92:381-9.

10. Timms DJ. The effect of rapid maxillary expansion on nasal airway resistance. Br J Orthod 1986;13:221-8.

11. Kilic N, Oktay $H$. Effects of rapid maxillary expansion on nasal breathing and some naso-respiratory and breathing problems in growing children: a literature review. Int $\mathrm{J}$ Pediatr Otorhinolaryngol 2008;72:1595-601

12. Buck LM, Dalci O, Darendeliler MA, Papadopoulou AK. Effect of Surgically Assisted Rapid Maxillary Expansion on Upper Airway Volume: A Systematic Review. J Oral Maxillofac Surg 2016;74:1025-43.

13. Romulo de Medeiros J, Ferraro Bezerra M, Gurgel Costa FW, Pinheiro Bezerra T, de Araujo Alencar CR, Studart Soares EC. Does pterygomaxillary disjunction in surgically assisted rapid maxillary expansion influence upper airway volume? A prospective study using Dolphin Imaging 3D. Int J Oral Maxillofac Surg 2017;46:1094-101.

14. Pereira-Filho VA, Monnazzi MS, Gabrielli MA, Spin-Neto R, Watanabe ER, Gimenez CM, et al. Volumetric upper airway assessment in patients with transverse maxillary deficiency after surgically assisted rapid maxillary expansion. Int J Oral Maxillofac Surg 2014;43:581-6.

15. Vinha PP, Faria AC, Xavier SP, Christino M, de Mello-Filho FV. Enlargement of the Pharynx Resulting From Surgically Assisted Rapid Maxillary Expansion. J Oral Maxillofac Surg 2016;74:369-79.

16. Landis JR, Koch GG. The measurement of observer agreement for categorical data. Biometrics 1977;33:159-74

17. Langer MR, Itikawa CE, Valera FC, Matsumoto MA, Anselmo-Lima WT. Does rapid maxillary expansion increase nasopharyngeal space and improve nasal airway resistance? Int J Pediatr Otorhinolaryngol 2011;75:122-5.

18. Usumez $S$, Iseri $H$, Orhan $M$, Basciftci FA. Effect of rapid maxillary expansion on nocturnal enuresis. Angle Orthod 2003;73:532-8.

19. Caprioglio A, Meneghel M, Fastuca R, Zecca PA, Nucera R, Nosetti L. Rapid maxillary expansion in growing patients: correspondence between 3-dimensional airway changes and polysomnography. Int $\mathrm{J}$ Pediatr Otorhinolaryngol 2014;78:23-7.

20. Smith T, Ghoneima A, Stewart K, Liu S, Eckert G, Halum S, et al. Three-dimensional computed tomography analysis of airway volume changes after rapid maxillary expansion. Am J Orthod Dentofacial Orthop 2012;141:618-26.

21. Ribeiro AN, de Paiva JB, Rino-Neto J, Illipronti-Filho E, Trivino $\mathrm{T}$, Fantini SM. Upper airway expansion after rapid maxillary expansion evaluated with cone beam computed tomography. Angle Orthod 2012;82:458-63.

22. Zeng J, Gao X. A prospective CBCT study of upper airway changes after rapid maxillary expansion. Int $\mathrm{J}$ Pediatr Otorhinolaryngol 2013;77:1805-10.

23. Kurt G, Altug-Atac AT, Atac MS, Karasu HA. Changes in nasopharyngeal airway following orthopedic and surgically assisted rapid maxillary expansion. J Craniofac Surg 2010;21:312-7.

24. Basciftci FA, Mutlu N, Karaman AI, Malkoc S, Kucukkolbasi H. Does the timing and method of rapid maxillary expansion have an effect on the changes in nasal dimensions? Angle Orthod 2002;72:118-23.

25. Akay MC, Aras I, Gunbay T, Aras A. Does transpalatal distraction affect pharyngeal airway dimensions and related soft tissues? J Oral Maxillofac Surg 2014;72:1559-64.

26. Nada RM, van Loon B, Schols JG, Maal TJ, de Koning MJ, Mostafa $\mathrm{YA}$, et al. Volumetric changes of the nose and nasal airway 2 years after tooth-borne and bone-borne surgically assisted rapid maxillary expansion. Eur J Oral Sci 2013;121:450-6.

27. Zhao Y, Nguyen M, Gohl E, Mah JK, Sameshima G, Enciso R. Oropharyngeal airway changes after rapid palatal expansion evaluated with cone-beam computed tomography. Am J Orthod Dentofacial Orthop 2010;137:S71-8. 


\section{Assessment of the effects of transpalatal distraction on pharyngeal airway dimensions}

\begin{abstract}
OBJECTIVE: This study was aimed to compare the pharyngeal airway dimensions before and after surgically-assisted maxillary expansion with a transpalatal distractor (TPD+SAME) in adult patients with a transverse maxillary deficiency (TMD).
\end{abstract}

Materials and Method: Patients who had more than $5 \mathrm{~mm}$ of TMD were included in this study. All patients underwent standard Le-Fort I osteotomies with maxillary midline osteotomy and maxillary expansion. Four months later, the distractor was removed, and transpalatal arch was applied. Before the operation and at least six months after the distraction, cone-beam computed tomography images were taken. Using the airway module of Dolphin 3D Surgery Imaging software, nasopharyngeal, retropalatal and retroglossal volumes, and the smallest cross-sectional area of the pharyngeal airway were measured. The nor- mal distribution assumption was controlled by using the Shapiro-Wilk test. Paired t-test was used for the measurements that had normal distribution, while the Wilcoxon test was used for the measurements that lacked normal distribution. Statistical significance was set at $\mathbf{p} \leq \mathbf{0 . 0 5}$.

Results: Nine female (42.9\%) and 12 male (57.1\%) patients (total 21) were included in this study. The mean age of the patients was $22.8 \pm 5.7$ years. The mean follow-up period was $22 \pm 11.1$ months. For the retropalatal, retroglossal, and total airway volumes and the minimum cross-sectional area of the pharyngeal airway, no statistically significant differences were found between the measurements obtained before and after the TPD+SAME treatment. However, there was a statistically significant difference between the measurements of the nasopharynx volume before and after the TPD+SAME treatment $(p \leq 0.05)$.

Conclusion: There was a significant increase in the nasopharyngeal volume after the TPD+SAME treatment. Volumetric and cross-sectional changes in other regions of the pharyngeal airway were not significant.

KEYwORDS: Maxillary osteotomy; palatal expansion technique; pharynx 